\title{
Three Dimensional MHD Hybrid Nanofluid Flow with Rotating Stretching/Shrinking Sheet and Joule Heating
}

\author{
Adnan Asghar ${ }^{1}$, Teh Yuan Ying ${ }^{1, *}$ \\ 1 School of Quantitative Sciences, UUM College of Arts \& Sciences, Universiti Utara Malaysia, 06010 UUM Sintok, Kedah Darul Aman, Malaysia
}

\section{\begin{tabular}{l} 
ARTICLE INFO ABSTRACT \\
\hline
\end{tabular}}

\section{Article history:}

Received 11 June 2021

Received in revised form 29 July 2021

Accepted 30 July 2021

Available online 8 August 2021

\section{Keywords:}

Boundary layer; heat transfer; hybrid nanofluid; magnetohydrodynamics (MHD); Joule heating; rotating stretching/shrinking sheet; suction
Hybrid nanofluid has a decent number of practical real-word applications. Previous studies found hybrid nanofluid possesses better heat transfer efficiency compared to nanofluid with single type of nanoparticle. However, the characteristics of boundary layer flow and heat transfer rate involving hybrid nanofluid could be further explored under higher-dimensional space with other physical assumptions surround the fluid flow. The main focus of the current study is to examine the three-dimensional hybrid nanofluid flow with rotating stretching/shrinking sheet under the influence of magnetic field and Joule heating using Tiwari-Das model. In addition, the influence of suction and stretching/ shrinking sheet on the variations of reduced skin friction, $g^{\prime}(0)$, and reduced heat transfer are studied as well. The fluid flow and heat transfer problem presented in this study is governed by a system of nonlinear partial differential equations (PDEs), which is then transformed into the corresponding system of high order nonlinear ordinary differential equations (ODEs) using similarity variables. The resulting system of higher order nonlinear ODEs is solved numerically using a boundary value solver known as bvp4c, which operates on the MATLAB computational platform. Results revealed that velocity profile of the hybrid nanofluid increases alongside with the value of magnetic parameter, but declination was observed in the profile of $g(\eta)$ and temperature for dual solutions, as the value of copper $(\mathrm{Cu})$ nanoparticles volume fraction increases. Furthermore, an increment in the value of the Eckert number causes the temperature of the hybrid nanofluid to rise as well for both dual solutions. In summary, dual solutions exist for shrinking sheet while unique solution is observed for stretching sheet with various values of $\mathrm{Cu}$ nanoparticles volume fraction and magnetic parameter. Dual solutions also exist for the value of the suction parameter greater than its critical point with various values of $\mathrm{Cu}$ nanoparticles volume fraction.

\section{Introduction}

Choi [1] suggested the term "nanofluids" to represent a kind of modern fluid which mixes the base fluid with nanoparticles. Organic liquids (such as refrigerants, ethylene, triethylene glycol, and etc.), oil and lubricants, solution of polymeric, water, and other common fluids can all be used as base fluids. On the other hand, nanoparticles refer to tiny particles of matter that are smaller than $100 \mathrm{~nm}$ in diameter. Commonly used nanoparticle materials are metal oxide (e.g. copper (II) oxide

\footnotetext{
* Corresponding author.

E-mail address: yuanying@uum.edu.my (Teh Yuan Ying)
}

https://doi.org/10.37934/cfdl.13.8.119 
$(\mathrm{CuO})$, silica $\left(\mathrm{SiO}_{2}\right)$, alumina $\left(\mathrm{Al}_{2} \mathrm{O}_{3}\right)$, titanium dioxide $\left(\mathrm{TiO}_{2}\right)$, and zirconia $\left.\left(\mathrm{ZrO}_{2}\right)\right)$, metal carbides (e.g. silicon carbide $(\mathrm{SiC})$ ), chemically stable metal (e.g. gold $(\mathrm{Au})$ and copper $(\mathrm{Cu})$ ), metal nitrides (e.g. aluminium nitride (AIN) and silicon nitride $\left.\left(\mathrm{Si}_{3} \mathrm{~N}_{4}\right)\right)$, and carbon in several forms (e.g. graphite, nanotubes, diamond, fullerene, and carbon (C)), to name a few [2,3]. Nanofluids are known to have better thermal properties than their base fluids, particularly in improving the thermal conductivity of the base fluids. Hence, nanofluids have many real-world applications which involve heat transfer. Notable applications can be found in solar energy, drug delivery, aerospace, agriculture, cooling and heat of buildings, automobiles, refrigerators, and microchips (Lund et al., [4]).

An early concept of two-dimensional steady flow of boundary layer through a stretching sheet was studied by Sakiadis [5]. Later, Crane [6] modernized the thought of Sakiadis [5] by applying a twodimensional steady flow over both linear and exponential stretching surfaces. Crane [6] suggested that the velocity at which a sheet was stretched from a slit is proportional to its distance. Since then, many past and recent studies in fluid mechanics still revolve around stretching sheet with a variety type of fluids. The stretching surface flow has an imperative role in several engineering and industrial fields, like manufacturing fiberglass, plate, and so on (Zaimi et al., [7]). Khan and Pop [8] published the first finding on stretching sheet in nanofluid where a steady boundary layer flow via the impacts of thermophoresis and Brownian motion were being considered in two-dimensional setting. While the stretching parameter was fixed at 1 throughout the entire article, they discovered that the reduced Nusselt number was a reducing function of Brownian motion number ( $\mathrm{Nb})$, thermophoresis number (Nt), Lewis number (Le), and Prandtl number ( $\mathrm{Pr})$. The shrinking sheet fluid flow has only recently obtained publicity. The fluid flow on the shrinking surface is measured for a large quantity of industrial usages. Dero et al., [9] analyzed the stability of a two-dimensional Casson based nanofluid model over a stretching and shrinking sheet using a single-phase model. They suggested the suspension of silver $(\mathrm{Ag})$ and $\mathrm{Cu}$ nanoparticles would reduce the velocity profile and related boundary layer thicknesses. Suspension of Ag nanoparticles within the Casson based nanofluid displayed a higher rate of heat transfer compared to $\mathrm{Cu}$ nanoparticles. Many researchers studied other types of nanofluid flow problems to determine the effects of various physical parameters on boundary layer flows over shrinking/stretching sheets, as well as curved surfaces [10-24].

Recently, many researchers have attempted to further enhance the heat transfer rate by incorporating more than one type of solid nanoparticles within a base fluid. Such incorporation has produced a new kind of fluid known as hybrid nanofluid. Devi and Devi [25] investigated a twodimensional hybrid nanofluid steady flow past a stretching layer. They recommended that hybrid nanofluid improvised cooling performance, as evidenced by the fact that the heat transmission rate of hybrid nanofluid ( $\mathrm{Cu}-\mathrm{Al}_{2} \mathrm{O}_{3} /$ Water) is faster than that of nanofluid ( $\mathrm{Cu} /$ Water). According to Huminic and Huminic [26], hybrid nanofluid has been used in a variety of applications such as plate heat exchangers, little channel heat sinks, microchannels, air conditioning systems, and etc. Waini et al., [27] investigated the influence of radiation on a two-dimensional steady flow across a nonlinear stretching/shrinking sheet involving hybrid nanofluid. They discovered that when the volume fraction of Cu nanoparticle in the upper branch solution increases, the skin friction coefficient also increases, but the local Nusselt number decreases on the shrinking layer. However, both skin friction coefficient as well as local Nusselt number decreased when the volume fraction of $\mathrm{Cu}$ nanoparticle in the lower branch solution increases. Under the effect of radiation, the temperature for both branches of the solution rises. After that, Waini et al., [28] discussed about a two-dimensional unsteady flow and heat transfer over a stretching and shrinking surface in hybrid nanofluid. Finding for the upper branch solution was similar to Waini et al., [27], but for the solution of lower branch, as the Cu nanoparticle volume fraction parameter enhances, the local Nusselt number as well as skin friction coefficient both decreases. Waini et al., [29] examined a two-dimensional hybrid nanofluid steady flow with 
buoyancy effects through an exponentially stretching/shrinking vertical surface towards a stagnation point. They observed an enhancement of the local Nusselt number and skin friction coefficient in the first solution when both volume fraction of $\mathrm{Cu}$ nanoparticle and buoyancy parameters increase. Furthermore, increment in both $\mathrm{Cu}$ nanoparticle volume fraction and buoyancy parameters also increases the velocity of the first solution, but this observation became reversed in the second solution. They also noticed temperature would be reduced in the first solution when the buoyancy parameter increases. However, the temperature for the first and second solutions was enhanced with the Cu nanoparticle volume fraction parameter. Many researchers studied other types of hybrid nanofluid flow problems in order to evaluate the effects of various physical parameters [30-33].

Rotational flow has many uses in sciences and engineering, such as thermal power generation systems, air-cleaning devices, gas turbine rotors, medical instruments, electronics devices, rotating machinery, computer storage equipment, and etc. Hayat and Nadeem [34] investigated the use of a three-dimensional steady $\mathrm{Ag}-\mathrm{CuO} /$ water hybrid nanofluid rotational flow to improve heat transfer. Under the effect of heat generation, chemical reactions, and radiation, they revealed that hybrid nanofluid has greater heat transfer rate than normal nanofluid. Furthermore, the concentration profile increased when the rotation parameter increased. Moreover, Hayat et al., [35] investigated a rotating three-dimensional flow of hybrid nanofluid via partial slip and radiation. They concluded that, as the rotational and radiation parameters increase, the temperature profile increases as well. After that, Anuar et al., [36] discussed a three-dimensional steady rotating and radiative flow across a stretching/shrinking surface involving hybrid nanofluid. They observed that the range of dual solutions was reduced as the value of the rotational parameter increases. The fundamental impact of stretching/shrinking sheet and rotating flow involving hybrid nanofluids have been broadly examined by several other authors [37-40].

Magnetohydrodynamics (MHD) is the study of the movement of electrically conducting fluids as in the existence of a magnetic field. Engineers used the MHD concept in the design of a wide range of applications in industries, notably in flow meters, space vehicle impulsion, nuclear waste disposal, MHD pumps, heat exchangers generators, nuclear reactor cooling, and geothermal energy extractors (Yashkun et al., [41]). Devi and Devi [25] investigated numerically a two-dimensional MHD steady hybrid nanofluid flow across a stretching plate with suction as well as Newtonian heating. They observed the increment in magnetic field strength has enhanced the hybrid nanofluid's temperature but reduced its velocity. Furthermore, Devi and Devi [42] extended their previous work in Devi and Devi [25] to a three-dimensional steady flow. The influence of magnetic field strength on the hybrid nanofluid's velocity and temperature in the three-dimensional steady flow was similar to the twodimensional steady flow reported in Devi and Devi [25]. Aly and Pop [43] further studied a twodimensional MHD hybrid nanofluid flow past a shrinking and stretching plate by convective boundary conditions and suction. They detected the addition of $\mathrm{Cu}$ nanoparticles to $\mathrm{Al}_{2} \mathrm{O}_{3} /$ water would cool the resultant hybrid nanofluid when the volume fraction of $\mathrm{Cu}$ nanoparticle, suction, and magnetic parameters were increased for a stretching/shrinking layer. Waini et al., [44] investigated the heat transfer of a two-dimensional steady hybrid nanofluid flow within an exponentially stretching/shrinking layer. They observed that the temperature increased the dual solutions as the effect of radiation was enhanced, but the temperature decreases in the first solution and increases in the second solution when the value of the magnetic parameter increases. Recently, Lund et al., [45] studied a two-dimensional unsteady MHD flow with radiation over a shrinking and stretching surface in hybrid nanofluid. They concluded that temperature was boosted when the radiation effect increased for both dual solutions. They also found out that the magnetic parameter's critical values were enhanced with the volume fraction of $\mathrm{Cu}$ nanoparticle parameter. Additional references of hybrid nanofluid in the direction of MHD can also be found in the existing literature [46-49]. 
Joule heating is the method of producing heat by conducting an electric current through a resistor, also identified as Ohmic heating (Yashkun et al., [41]). Joule heating is used in many applications, for instance, incandescent light bulb, cartridge heaters, resistance ovens, electric heaters, food processing apparatus, soldering irons, electric fuses, and electric stoves, to name a few (Yashkun et al., [41]). A two-dimensional MHD steady hybrid nanofluid flow by a radially stretching/shrinking sheet through Joule heating was investigated by Khashi'ie et al., [50]. They mentioned about Eckert number parameter did not affect the boundary layer separation, but a higher suction parameter value could have an influence on heat transfer efficiency. Yan et al., [51] examined a two-dimensional MHD steady hybrid nanofluid flow that passes through an exponential surface with Joule heating. Observation on the first solution revealed that the skin friction coefficient was enhanced along with the magnetic and suction parameters, but the said coefficient decreases under the influence of the velocity slip factor. The temperature in dual solutions rises as the Eckert number increases. However, no shift in boundary layer separation was observed for different Eckert number parameters. Yashkun et al., [41] explored the heat transfer behavior of a two-dimensional steady flow within an exponentially stretching/shrinking layer, as well as Joule heating and mixed convection in hybrid nanofluid. Finding on the influence of Eckert number on the temperature of dual solutions was found similar to Yan et al., [51]. Furthermore, Eckert number did not affect the variation of reduced skin friction since it remains the same for increasing values of Eckert number. The Joule heating effect along various flow configurations and physical consequences may also be studied in the current literature [52-55].

Researches on the hybrid nanofluid with the effect of MHD and Joule heating were currently limited in the case of two-dimensional steady flow (see Yashkun et al., [41], Khashi'ie et al., [50], Yan et al., [51]). From the literature review on preceding studies, it is crucial to consider such a problem as three-dimensional flow as this setting allows more comprehensive and realistic applications in the real-world. Anuar et al., [36] have considered a three-dimensional hybrid nanofluid flow over rotating stretching/shrinking sheet with the effect of radiation but without paying the attention to the influence of MHD and Joule heating. Therefore, this current study extended the work of Anuar et al., [36] by including the effect of MHD and Joule heating via Tiwari-Das model (see Tiwari and Das [56]). Hence, a novel physical model of three-dimensional steady MHD hybrid nanofluid flow past a linear rotating stretching/shrinking sheet with Joule heating is obtained for this study. The proposed model might find its application in the compressor of the refrigeration system. Hybrid nanofluid as the refrigerant, is moved through the entire refrigeration system using the compressor which indeed is a pump consists of a rotating motor driven by the magnetic field. The compressor also has an overload protector which prevents the compressor from overheat while working. Therefore, Joule heating occurred while the overload protector works as a resistor.

The hybrid nanofluid considered in this study is prepared by first releasing alumina $\left(\mathrm{Al}_{2} \mathrm{O}_{3}\right)$ into the water to form an $\mathrm{Al}_{2} \mathrm{O}_{3}$ /water nanofluid. After that, copper $(\mathrm{Cu})$ is mixed into the $\mathrm{Al}_{2} \mathrm{O}_{3} /$ water nanofluid and forms an $\mathrm{Al}_{2} \mathrm{O}_{3}-\mathrm{Cu}$ /water hybrid nanofluid. The effects of suction and stretching sheet on the variations of reduced heat transfer and reduced skin friction are studied. Moreover, the temperature and velocity profiles for various rotation and magnetic parameters are examined and presented as well.

\section{Methodology}

\subsection{Mathematical Modelling}

Figure 1 depicts the three-dimensional $\mathrm{MHD} \mathrm{Al}_{2} \mathrm{O}_{3}-\mathrm{Cu}$ /water hybrid nanofluid flow with heat transfer over a permeable rotating shrinking/stretching sheet which can be represented in three- 
dimensional Cartesian coordinate system (or three-dimensional space). The hybrid nanofluid is assumed to be a steady, laminar, Newtonian, and incompressible flow which occupied the upper halfspace at $z \geq 0$. It is noted that the $x$-axis and $y$-axis are measured in the plane $z=0$. The sheet at $z=0$ has a few assumptions as follows

i. It is considered to stretch/shrink in the $x$-direction only with velocity $U_{w}=a x$ where $a$ is a constant,

ii. It rotates with a constant velocity $\Omega$ about the vertical $z$-axis, where $z$ is the coordinate measured perpendicular to the sheet, and

iii. It is influenced by a uniform magnetic field of strength $B$ being applied in the direction parallel to the $z$-axis.

The temperature at the stretching/shrinking sheet is $T_{w}=T_{0} x^{2}$, where $T_{0}$ is the characteristic temperature (Lund et al., [57]), while the ambient temperature is denoted by $T_{\infty}$. Additional assumption requires nanoparticle as well as fluid phases to achieve the state of thermal equilibria (Anuar et al., [36]). Besides, velocity slip between the phases can be neglected since the shape and size of the nanoparticles are uniform and significantly small, respectively (Anuar et al., [36]).
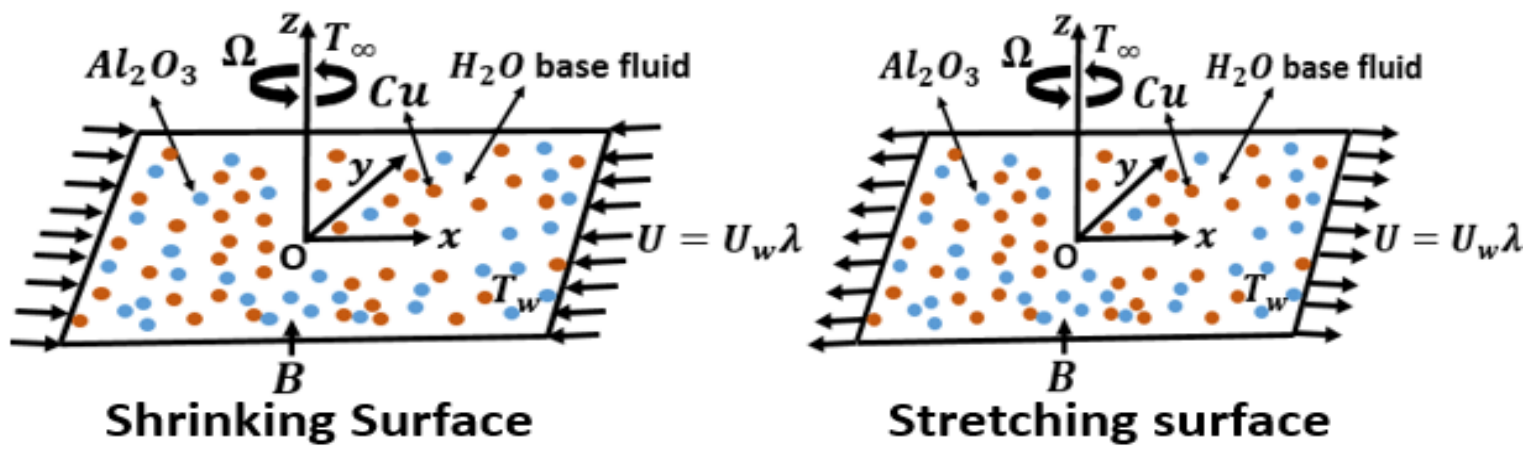

Fig. 1. The physical model considered in this study

The above-mentioned physical model can be represented by the basic steady conservation of mass, momentum, and thermal energy governing equations as follows (Yashkun et al., [41]; Anuar et al., [36])

$\frac{\partial u}{\partial x}+\frac{\partial v}{\partial y}+\frac{\partial w}{\partial z}=0$

$u \frac{\partial u}{\partial x}+v \frac{\partial u}{\partial y}+w \frac{\partial u}{\partial z}-2 \Omega v=\frac{\mu_{h n f}}{\rho_{h n f}} \frac{\partial^{2} u}{\partial z^{2}}-\frac{\sigma_{h n f}}{\rho_{h n f}} B^{2} u$,

$u \frac{\partial v}{\partial x}+v \frac{\partial v}{\partial y}+w \frac{\partial v}{\partial z}+2 \Omega u=\frac{\mu_{h n f}}{\rho_{h n f}} \frac{\partial^{2} v}{\partial z^{2}}-\frac{\sigma_{h n f}}{\rho_{h n f}} B^{2} v$

$u \frac{\partial T}{\partial x}+v \frac{\partial T}{\partial y}+w \frac{\partial T}{\partial z}=\frac{k_{h n f}}{\left(\rho c_{p}\right)_{h n f}} \frac{\partial^{2} T}{\partial z^{2}}+\frac{\sigma_{h n f}}{\left(\rho c_{p}\right)_{h n f}} B^{2}\left(u^{2}+v^{2}\right)$,

with boundary conditions

$u=\lambda U_{w}, v=0, w=w_{w}, T=T_{w}=T_{0} x^{2}+T_{\infty}$ as $z=0$, 
$u \rightarrow 0, v \rightarrow 0, T \rightarrow T_{\infty}$ as $z \rightarrow \infty$,

where $u, v$ and $w$ are the velocity components in the $x, y$ and $z$ directions, respectively, $T$ is the temperature, $\Omega$ is the angular velocity, and $B$ is the magnitude of the magnetic field strength. Moreover, $c_{p}, \mu, \rho, k$, and $\sigma$ denote the specific heat capacity, dynamic viscosity, density, thermal conductivity, and electrical conductivity, respectively. In addition, $\lambda$ is the constant stretching and shrinking parameters with $\lambda=0$ for the static sheet, $\lambda<0$ for shrinking case, and $\lambda>0$ for the stretching; and $w_{w}$ is the constant mass flux velocity with $w_{w}>0$ for suction and $w_{w}<0$ for injection.

The subscripts ' $f$ ', ' $n f$ ', ' $h n f^{\prime}$ ', ' 1 ' and ' 2 ' stand for 'base fluid', 'nanofluid', 'hybrid nanofluid', 'solid nanoparticle $1\left(\mathrm{Al}_{2} \mathrm{O}_{3}\right)^{\prime}$ ' and 'solid nanoparticle $2(\mathrm{Cu})^{\prime}$ '. Following the definitions of the subscripts, Table 1 gives the thermophysical properties employed in Eq. (2)-(4). From Table $1, \varphi_{1}$ and $\varphi_{2}$ denote the volume fraction parameter for nanoparticles $\mathrm{Al}_{2} \mathrm{O}_{3}$ and $\mathrm{Cu}$, respectively, while $\sigma_{1}$ and $\sigma_{2}$ represent the electric conductivity parameter for nanoparticles $\mathrm{Al}_{2} \mathrm{O}_{3}$ and $\mathrm{Cu}$, respectively.

Table 1

Thermophysical properties of hybrid nanofluid (Yashkun et al., [41])

\begin{tabular}{ll}
\hline Properties & Hybrid Nanofluid \\
\hline Dynamic Viscosity & $\mu_{h n f}=\frac{\mu_{f}}{\left(1-\varphi_{2}\right)^{2.5}\left(1-\varphi_{1}\right)^{2.5}}$ \\
Density & $\rho_{h n f}=\left(1-\varphi_{2}\right)\left[\left(1-\varphi_{1}\right) \rho_{f}+\varphi_{1} \rho_{1}\right]+\varphi_{2} \rho_{2}$ \\
Thermal conductivity & $k_{h n f}=\frac{k_{2}+2 k_{n f}-2 \varphi_{2}\left(k_{n f}-k_{2}\right)}{k_{2}+2 k_{n f}+\varphi_{2}\left(k_{n f}-k_{2}\right)} \times k_{n f}$ where $k_{n f}=\frac{k_{1}+2 k_{f}-2 \varphi_{1}\left(k_{f}-k_{1}\right)}{k_{1}+2 k_{f}+\varphi_{1}\left(k_{f}-k_{1}\right)} \times k_{f}$ \\
Volumetric heat capacity & $\left(\rho c_{p}\right)_{h n f}=\left(1-\varphi_{2}\right)\left[\left(1-\varphi_{1}\right)\left(\rho c_{p}\right)_{f}+\varphi_{1}\left(\rho c_{p}\right)_{1}\right]+\varphi_{2}\left(\rho c_{p}\right)_{2}$ \\
Electrical conductivity & $\sigma_{h n f}=\frac{\sigma_{2}+2 \sigma_{n f}-2 \varphi_{2}\left(\sigma_{n f}-\sigma_{2}\right)}{\sigma_{2}+2 \sigma_{n f}+\varphi_{2}\left(\sigma_{n f}-\sigma_{2}\right)} \times \sigma_{n f}$ where $\sigma_{n f}=\frac{\sigma_{1}+2 \sigma_{f}-2 \varphi_{1}\left(\sigma_{f}-\sigma_{1}\right)}{\sigma_{1}+2 \sigma_{f}+\varphi_{1}\left(\sigma_{f}-\sigma_{1}\right)} \times \sigma_{f}$ \\
\hline
\end{tabular}

The thermophysical properties of the nanoparticles (i.e. $\mathrm{Al}_{2} \mathrm{O}_{3}$ and $\mathrm{Cu}$ ) and base fluid (water) are shown in Table 2.

Table 2

Thermophysical properties of nanoparticles and base fluid (water) (Yashkun et al., [41]; Anuar et al., [36])

\begin{tabular}{llllll}
\hline & $\rho\left(\mathrm{kgm}^{-3}\right)$ & $c_{p}\left(\mathrm{Jkg}^{-1} \mathrm{~K}^{-1}\right)$ & $k\left(\mathrm{Wm}^{-1} \mathrm{~K}^{-1}\right)$ & $\sigma\left(\mathrm{Sm}^{-1}\right)$ & $\mathrm{Pr}$ \\
\hline Water $\left(\mathrm{H}_{2} \mathrm{O}\right)$ & 997.1 & 4179 & 0.613 & 0.05 & 6.2 \\
Alumina $\left(\mathrm{Al}_{2} \mathrm{O}_{3}\right)$ & 3970 & 765 & 40 & $5.96 \times 10^{7}$ & - \\
Copper $(\mathrm{Cu})$ & 8933 & 385 & 400 & $3.69 \times 10^{7}$ & - \\
\hline
\end{tabular}

The governing equations in Eq. (1)-(4) and boundary conditions in Eq. (5)-(6) can be transformed to a system of nonlinear ordinary differential equations (ODEs) by the following similarity variables (Sajid et al., [58]; Anuar et al., [36])

$u=a x f^{\prime}(\eta), v=\operatorname{axg}(\eta), w=-\sqrt{a v_{f}} f(\eta), \theta(\eta)=\frac{T-T_{\infty}}{T_{w}-T_{\infty}}, \eta=z \sqrt{\frac{a}{v_{f}}}$

where $a$ is a positive constant and $v_{f}$ is the kinematic viscosity of the base fluid. However, Eq. (1) is automatically satisfied after applying the similarity variables in Eq. (7). On substituting the similarity variables in Eq. (7) into the remaining Eq. (2)-(6), the following system of higher order nonlinear ODEs is obtained 
$\frac{\mu_{h n f} / \mu_{f}}{\rho_{h n f} / \rho_{f}} f^{\prime \prime \prime}-\left(f^{\prime}\right)^{2}+f f^{\prime \prime}+2 \omega g-\frac{\sigma_{h n f} / \sigma_{f}}{\rho_{h n f} / \rho_{f}} \mathrm{M} f^{\prime}=0$,

$\frac{\mu_{h n f} / \mu_{f}}{\rho_{h n f} / \rho_{f}} g^{\prime \prime}+f g^{\prime}-f^{\prime} g-2 \omega f^{\prime}-\frac{\sigma_{h n f} / \sigma_{f}}{\rho_{h n f} / \rho_{f}} M g=0$,

$\frac{1}{\operatorname{Pr}\left(\rho c_{p}\right)_{h n f} /\left(\rho c_{p}\right)_{f}}\left\{\frac{k_{h n f}}{k_{f}}\right\} \theta^{\prime \prime}+f \theta^{\prime}-2 f^{\prime} \theta+\frac{\sigma_{h n f} / \sigma_{f}}{\left(\rho c_{p}\right)_{h n f} /\left(\rho c_{p}\right)_{f}} \operatorname{MEc}\left(f^{\prime 2}+g^{2}\right)=0$,

as well as the boundary conditions

$f(0)=S, g(0)=0, f^{\prime}(0)=\lambda, \theta(0)=1$,

$f^{\prime}(\eta) \rightarrow 0, g(\eta) \rightarrow 0, \theta(\eta) \rightarrow 0$ as $\eta \rightarrow \infty$,

where the Prandtl number is signified by the symbol Pr, $\omega$ is the rotation parameter, M stands for the magnetic parameter and Ec is the Eckert number, that are defined by

$\operatorname{Pr}=\frac{\left(\mu c_{p}\right)_{f}}{k_{f}}, \omega=\frac{\Omega}{a}, \mathrm{M}=\frac{B^{2} \sigma_{f}}{a \rho_{f}}, \mathrm{Ec}=\frac{a^{2}}{T_{0}\left(c_{p}\right)_{f}}$.

Besides, the parameter of suction/injection is denoted by $S$, where $S>0$ corresponds to suction and $S<0$ for injection.

The physical quantities of interest are the skin friction coefficients along the $x$-axis and $y$-axis that are represented by $C_{f x}$ and $C_{f y}$, respectively, and the local Nusselt number $N u_{x}$; all of which are described as

$C_{f x}=\frac{\mu_{h n f}}{\rho_{f}\left(U_{w}\right)^{2}}\left(\frac{\partial u}{\partial z}\right)_{z=0}, C_{f y}=\frac{\mu_{h n f}}{\rho_{f}\left(U_{w}\right)^{2}}\left(\frac{\partial v}{\partial z}\right)_{z=0}, N u_{x}=\frac{-x k_{h n f}}{k_{f}\left(T_{w}-T_{\infty}\right)}\left(\frac{\partial T}{\partial z}\right)_{z=0}$.

On applying the similarity variables in Eq. (7) into Eq. (14), the following Eq. (15) is obtained

$\sqrt{\operatorname{Re}_{x}} C_{f x}=\frac{\mu_{h n f}}{\mu_{f}} f^{\prime \prime}(0), \sqrt{\operatorname{Re}_{x}} C_{f y}=\frac{\mu_{h n f}}{\mu_{f}} g^{\prime}(0), \frac{N u_{x}}{\sqrt{\operatorname{Re}_{x}}}=-\frac{k_{h n f}}{k_{f}} \theta^{\prime}(0)$,

where, $\operatorname{Re}_{x}=\frac{U_{w} x}{v_{f}}$ is the local Reynolds number.

\subsection{Numerical Method}

The system of higher order nonlinear ODEs shown in Eq. (8)-(10) with the boundary conditions in Eq. (11)-(12) are solved numerically using bvp4c solver, which operates on the MATLAB computational platform. The bvp4c solver embedded the three-stage Lobatto IIIA Runge-Kutta method and returns numerical solutions of fourth order accuracy (Hale [59]). To implement bvp4c solver to our physical model, the following steps have been taken.

STEP 1: New variables are introduced for the system of higher order nonlinear ODEs in Eq. (8)-(10) 
$y(1)=f, y(2)=f^{\prime}, y(3)=f^{\prime \prime}, y(4)=g, y(5)=g^{\prime}, y(6)=\theta, y(7)=\theta^{\prime}$.

STEP 2: Reduce the system of higher order nonlinear ODEs in Eq. (8)-(10) to a system of first order nonlinear ODEs using the new variables in Eq. (16)

$f^{\prime}=y(2)$,

$f^{\prime \prime}=y(3)$,

$f^{\prime \prime \prime}=\left((y(2))^{2}-y(1) y(3)-2 \Omega y(4)+\frac{\sigma_{h n f} / \sigma_{f}}{\rho_{h n f} / \rho_{f}} \mathrm{M} \cdot y(2)\right) \frac{\rho_{h n f} / \rho_{f}}{\mu_{h n f} / \mu_{f}}$,

$g^{\prime}=y(5)$,

$g^{\prime \prime}=\left(y(2) y(4)-y(1) y(5)+2 \Omega y(2)+\frac{\sigma_{h n f} / \sigma_{f}}{\rho_{h n f} / \rho_{f}} \mathrm{M} \cdot y(4)\right) \frac{\rho_{h n f} / \rho_{f}}{\mu_{h n f} / \mu_{f}}$,

$\theta^{\prime}=y(7)$,

$\theta^{\prime \prime}=\left(2 y(2) y(6)-y(1) y(7)-\frac{\sigma_{h n f} / \sigma_{f}}{\left(\rho c_{p}\right)_{h n f} /\left(\rho c_{p}\right)_{f}} \mathrm{M} \cdot \operatorname{Ec}\left((y(2))^{2}+(y(4))^{2}\right)\right) \frac{\operatorname{Pr}\left(\rho c_{p}\right)_{h n f} /\left(\rho c_{p}\right)_{f}}{k_{h n f} / k_{f}}$.

STEP 3: Express the boundary conditions in Eq. (11)-(12) in terms of the new variables in Eq. (16)

$y(1)_{a}=S, y(4)_{a}=0, y(2)_{a}=\lambda, y(6)_{a}=1, y(2)_{b}=0, y(6)_{b}=0, y(4)_{b}=0$.

The subscripts ' $a$ ' and ' $b$ ' indicate the location the sheet at $\eta=0$, and the location away from the sheet for a specific value of $\eta$. In this study, this location is set at $\eta=20$.

STEP 4: Code the system of first order nonlinear ODEs in Eq. (17) along with the boundary conditions in Eq. (18) in bvp4c solver.

STEP 5: Obtain the first and second solutions by using two different set of initial guesses, one set at a time when executing the bvp4c solver. A set of initial guesses will be accepted if the computed temperature and velocity profiles fulfil Eq. (11)-(12), otherwise repeat this step with another new set of initial guesses. Several attempts are usually required before obtaining a satisfying set of initial guesses.

\section{Results and Discussion}

Firstly, to validate the physical model proposed in this study, the reduced skin friction $f^{\prime \prime}(0)$ and $g^{\prime}(0)$ for pure water $\left(\varphi_{1}=\varphi_{2}=0\right)$ with varying values of rotational parameter $\omega$, are compared with existing results obtained from Mustafa et al., [60] and Anuar et al., [36] for stretching sheet $\lambda=$ 1 and without the presence of suction and magnetic field. Such comparisons are tabulated in Table 3.

Table 3

Comparison of the values for $f^{\prime \prime}(0)$ and $g^{\prime}(0)$ when $\varphi_{1}=\varphi_{2}=0, S=0, \mathrm{M}=0$, Ec $=0.1, \lambda=1$, Pr $=$ 6.2

\begin{tabular}{lllllll}
\hline & \multicolumn{2}{l}{ Mustafa et al., [60] } & \multicolumn{2}{l}{ Anuar et al., [36] } & \multicolumn{2}{l}{ Current study } \\
$\omega$ & $f^{\prime \prime}(0)$ & $g^{\prime}(0)$ & $f^{\prime \prime}(0)$ & $g^{\prime}(0)$ & $f^{\prime \prime}(0)$ & $g^{\prime}(0)$ \\
\hline 0 & -1 & 0 & -1 & 0 & -1 & 0 \\
0.5 & -1.13838 & -0.51276 & -1.13838 & -0.51276 & -1.138374 & -0.512760 \\
1.0 & -1.32503 & -0.83709 & -1.32503 & -0.83710 & -1.325029 & -0.837097 \\
\hline
\end{tabular}


From Table 3, it is noticed that current findings agree with those results obtained from previous studies. Thus, Table 3 successfully validated the physical model proposed in this study as well as the coding in the bvp4c solver.

The effects of $\varphi_{2}$ on the reduced skin friction $f^{\prime \prime}(0), g^{\prime}(0)$ and reduced heat transfer $-\theta^{\prime}(0)$ against various values of suction parameter $S$ are given in Figures 2-4 for shrinking sheet $\lambda=-1$. The selected values of $\varphi_{2}$ in Figures 2-4 lies within the range values of $\varphi_{2} \in[0,0.2]$ as recommended by Tiwari and Das [56]. Here, $S_{c}$ denotes the critical point of the suction parameter, where both first and second solutions meet each other. From Figures 2-4, no solution is observed when $S<S_{c}$. Furthermore, the values of $S_{c}=1.8599,1.7299$, and 1.6190 are corresponding critical points of $\varphi_{2}=$ $0,0.05$ and 0.1 , respectively. This signifies that the boundary layer separation has been extended as $\varphi_{2}$ increases. From Figure 2, when the value of $\varphi_{2}$ varies from 0 to 0.1 , the value of the skin friction $f^{\prime \prime}(0)$ ascents in the first solution but declines in the second solution. In Figure 3 , there is no obvious variation in the value of $g^{\prime}(0)$ within the first solution as $\varphi_{2}$ rises, as opposed to the increasing trend of $g^{\prime}(0)$ being observed within the second solution. As in Figure 4 , the value of $-\theta^{\prime}(0)$ decreases with an increment of $\varphi_{2}$ in both solutions.

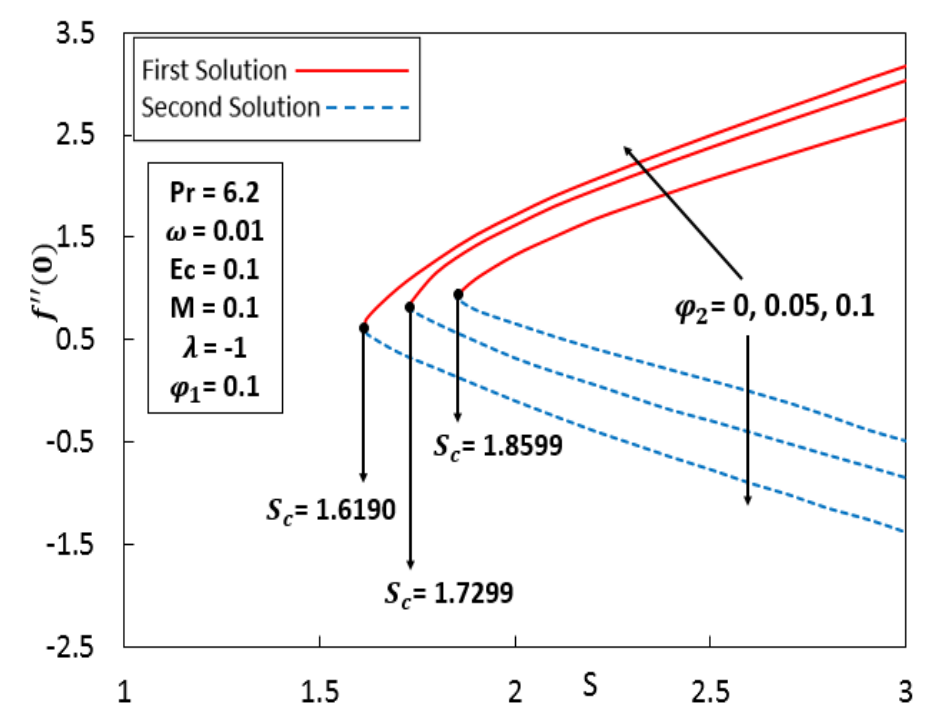

Fig. 2. Effect of $\varphi_{2}$ on $f^{\prime \prime}(0)$ with respect to $S$

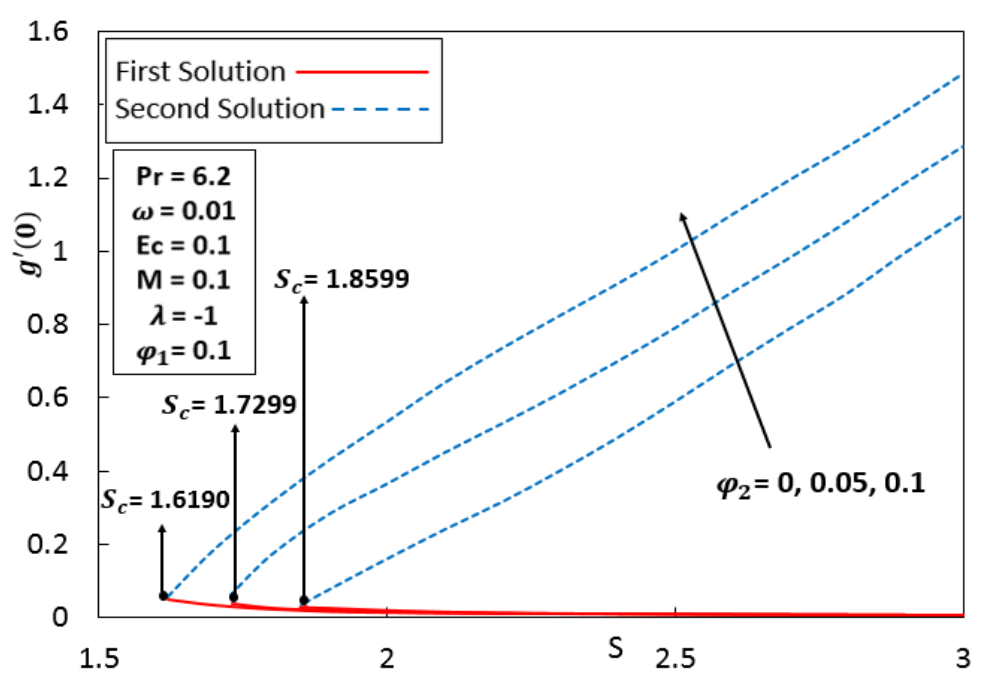

Fig. 3. Effect of $\varphi_{2}$ on $g^{\prime}(0)$ with respect to $S$ 


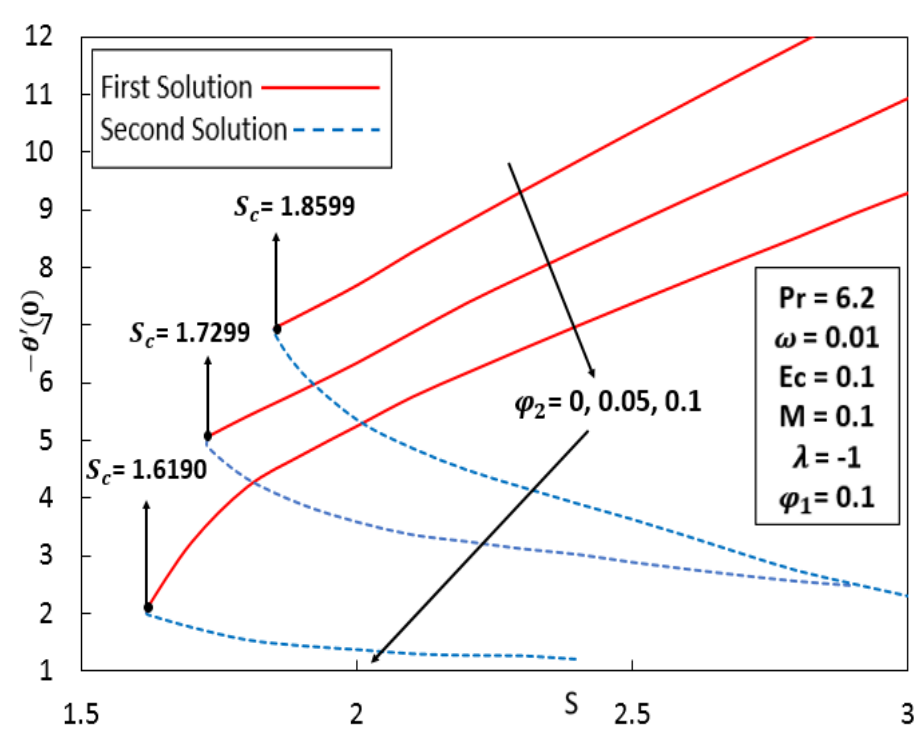

Fig. 4. Effect of $\varphi_{2}$ on $-\theta^{\prime}(0)$ with respect to $S$

Figures 5-7 demonstrate the variation of the reduced skin friction $f^{\prime \prime}(0), g^{\prime}(0)$ and reduced heat transfer $-\theta^{\prime}(0)$ with respect to the stretching or shrinking parameter $\lambda$ for different values of $\varphi_{2}$. The selected values of $\varphi_{2}$ in Figures 5-7 follow the values of $\varphi_{2}$ chosen by Anuar et al., [36]. From Figures 5-7, dual solutions are detected in the shrinking region for $\lambda \in\left[\lambda_{c},-1\right]$ as $\lambda_{c}$ denotes the critical point. On the other hand, unique solution generally exists in both shrinking and stretching regions for values of $\lambda>-1$. The solution domain has been extended leftward for every increment in $\varphi_{2}$. That being said, the values of $\lambda_{c}=-1.3263,-1.3608$ and -1.3901 are the corresponding critical points of $\varphi_{2}=0,0.01$, and 0.02 , respectively. This also proved that the boundary separation has been delayed as $\varphi_{2}$ increases. Figure 5 shows an increment in $\varphi_{2}$ rises the value of $f^{\prime \prime}(0)$ for the first solution when $\lambda_{c} \leq \lambda \leq 0$ and decreases this value when $\lambda>0$. However, the value of $f^{\prime \prime}(0)$ for the second solution decreases as $\varphi_{2}$ ascents within the range $\lambda_{c} \leq \lambda \leq 0$. In Figure 6 , no obvious variation in the value of $g^{\prime}(0)$ is noticed within the first solution as $\varphi_{2}$ rises but find an obvious decrement in the value of $g^{\prime}(0)$ within the second solution. Figure 7 witnesses a decrement in the value of $-\theta^{\prime}(0)$ for both solutions as $\varphi_{2}$ increases. Similar observations can also be found in Anuar et al., [36].

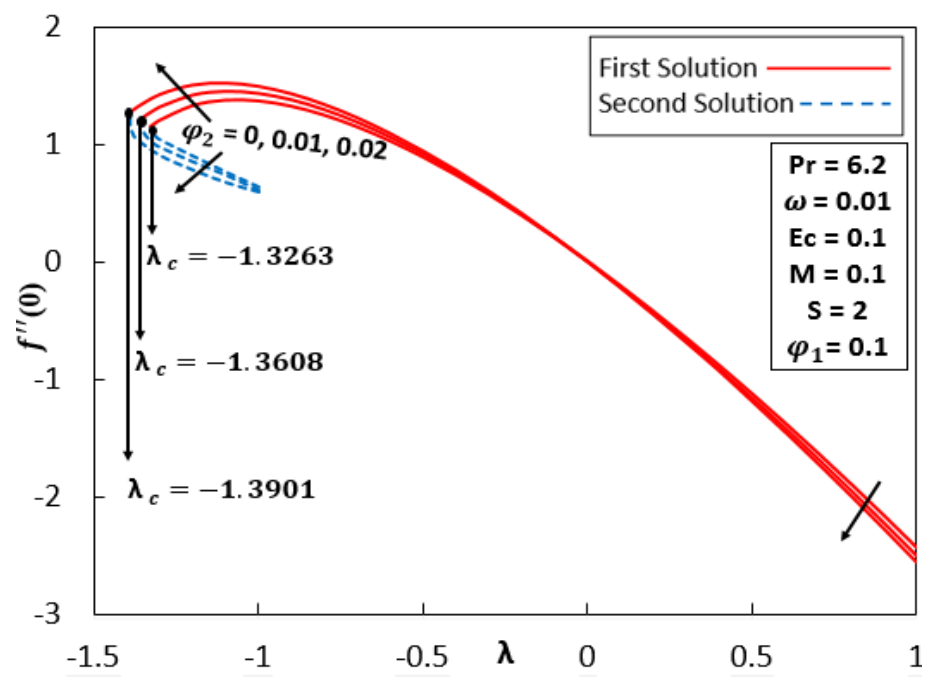

Fig. 5. Effect of $\varphi_{2}$ on $f^{\prime \prime}(0)$ with respect to $\lambda$ 


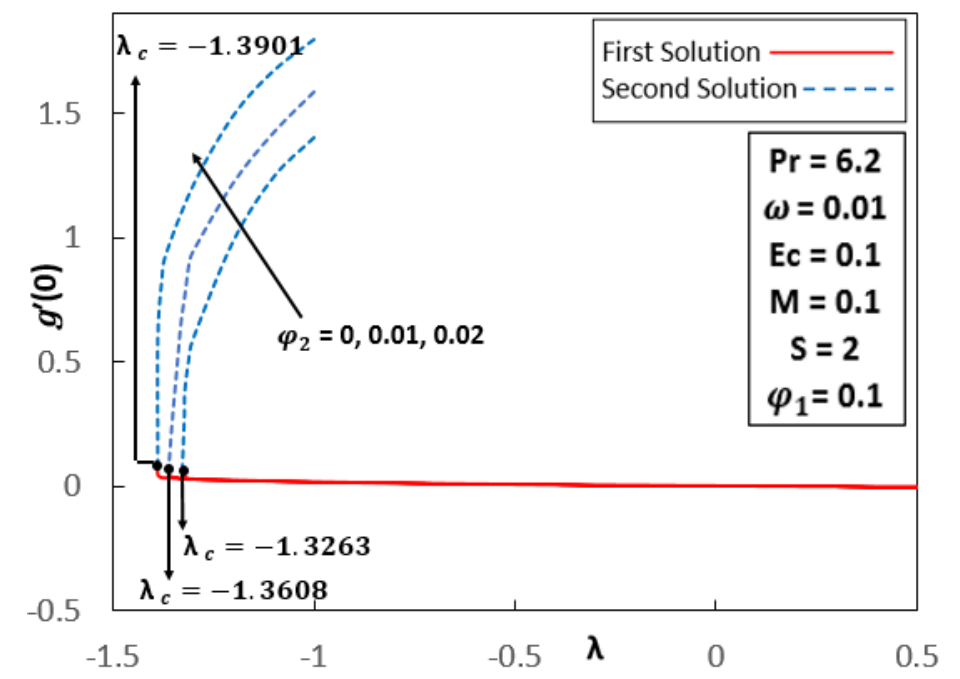

Fig. 6. Effect of $\varphi_{2}$ on $g^{\prime}(0)$ with respect to $\lambda$

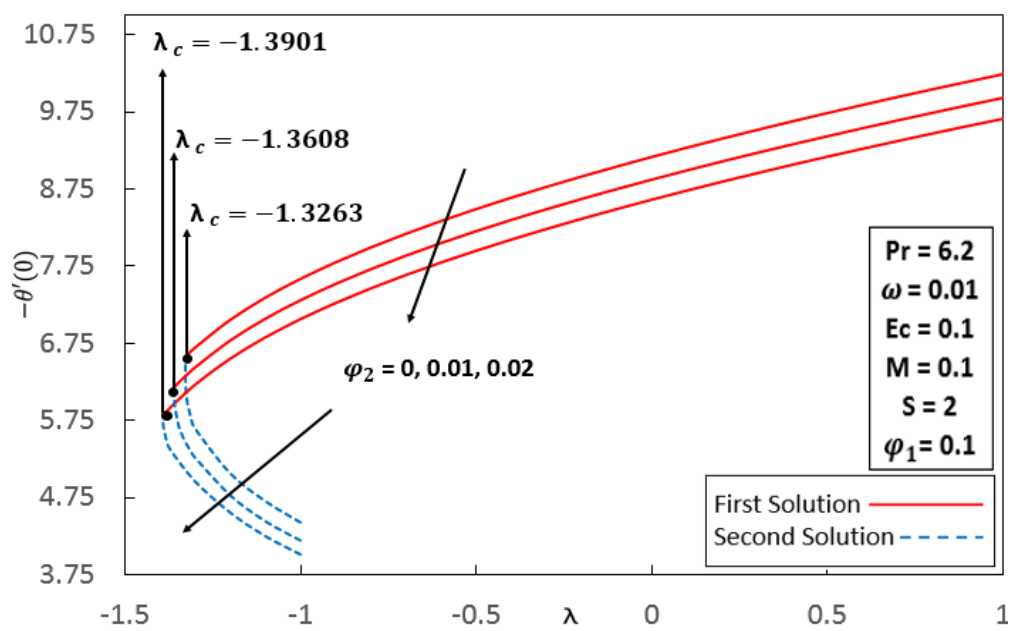

Fig. 7. Effect of $\varphi_{2}$ on $-\theta^{\prime}(0)$ with respect to $\lambda$

Figures 8-10 show the impacts of magnetic parameter M towards the velocity profile $f^{\prime}(\eta), g(\eta)$ and temperature profile $\theta(\eta)$, respectively. It was detected from Figure 8 that the velocity of the hybrid nanofluid increases as the values of $M$ is increased for both solutions. Figures 9-10 show that both $g(\eta)$ and temperature decline for both solutions as the values of $\mathrm{M}$ increases.

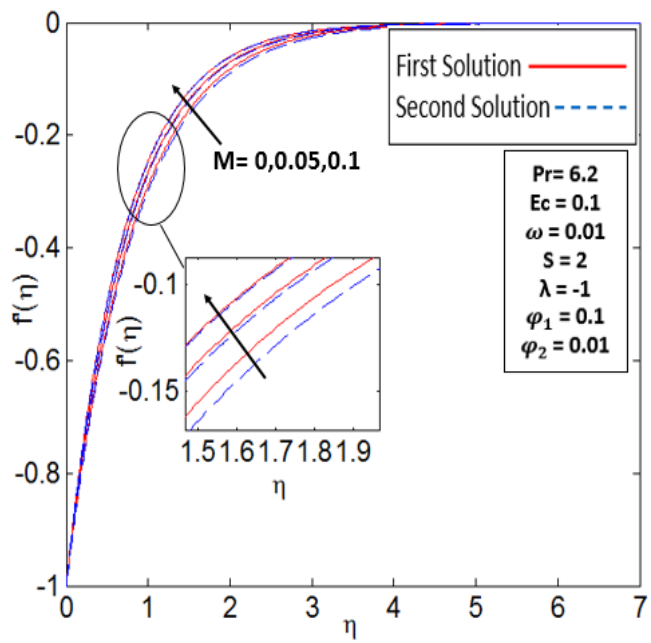

Fig. 8. Velocity profile for different $\mathrm{M}$ 


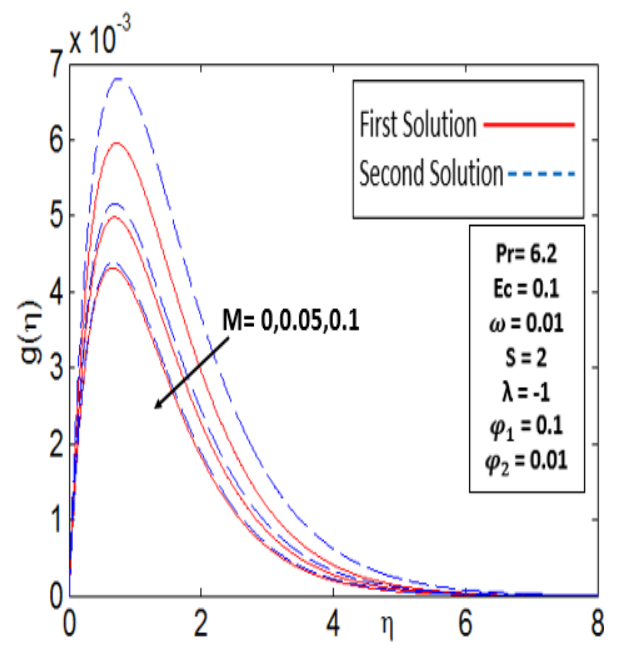

Fig. 9. Profile of $g(\eta)$ for different M

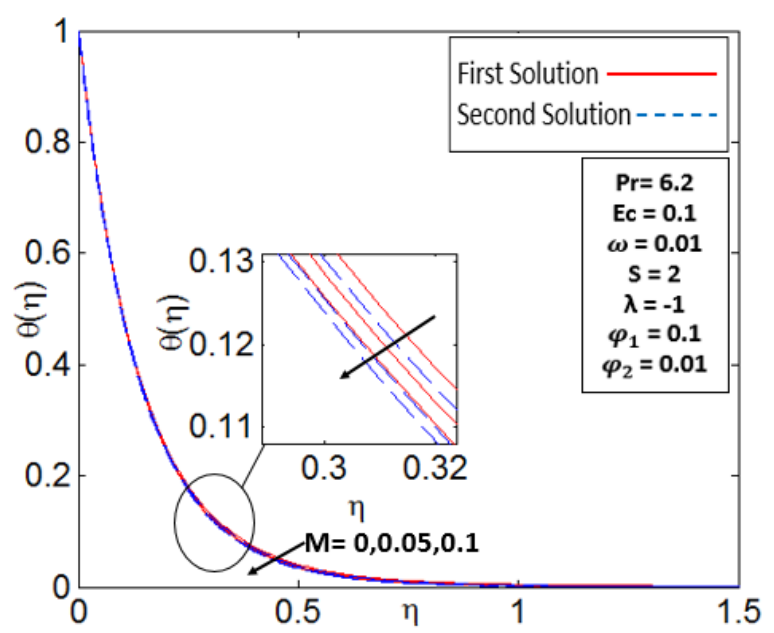

Fig. 10. Temperature profile for different $M$

Figures 11-13 depict the variation of the reduced skin friction $f^{\prime \prime}(0), g^{\prime}(0)$ and reduced heat transfer $-\theta^{\prime}(0)$ with respect to the stretching or shrinking parameter $\lambda$ for different values of the magnetic parameter $\mathrm{M}$. It is worth noting that the various values of $\mathrm{M}$ used in Figures 8-13 are quite common in the literature, as Khashi'ie et al., [50] used a wider range of $M$ (i.e. $0 \leq M \leq 3$ ) in their study. Figures 11-13 showed that dual solutions occur in the shrinking region for $\lambda \in\left[\lambda_{c},-1\right]$ such that the values of $\lambda_{c}=-1.4303,-1.8440$, and -2.3000 are the corresponding critical points of $\mathrm{M}=0,0.5$, and 1 , respectively. Thus, the boundary separation was retarded as the value of $M$ increases. This situation takes place when the Lorentz force overpowered the vorticity created by the shrinking sheet within the boundary layer. Figure 11 observed an increment in $\mathrm{M}$ raises the value of $f^{\prime \prime}(0)$ for the first solution for $\lambda_{c} \leq \lambda \leq 0$ and decreases this value when $\lambda>0$. Moreover, the value of $f^{\prime \prime}(0)$ for the second solution declines as $M$ rises for $\lambda_{c} \leq \lambda \leq 0$. Figure 12 observed a slight decrement in the value of $g^{\prime}(0)$ for both solutions as $M$ increases. Figure 13 showed an increment in $M$ enhances the values of $-\theta^{\prime}(0)$ for the first solution and declines in the second solution. Similar observations on the reduced skin friction $f^{\prime \prime}(0)$ and reduced heat transfer $-\theta^{\prime}(0)$ can also be found in Yashkun et al., [41]. 


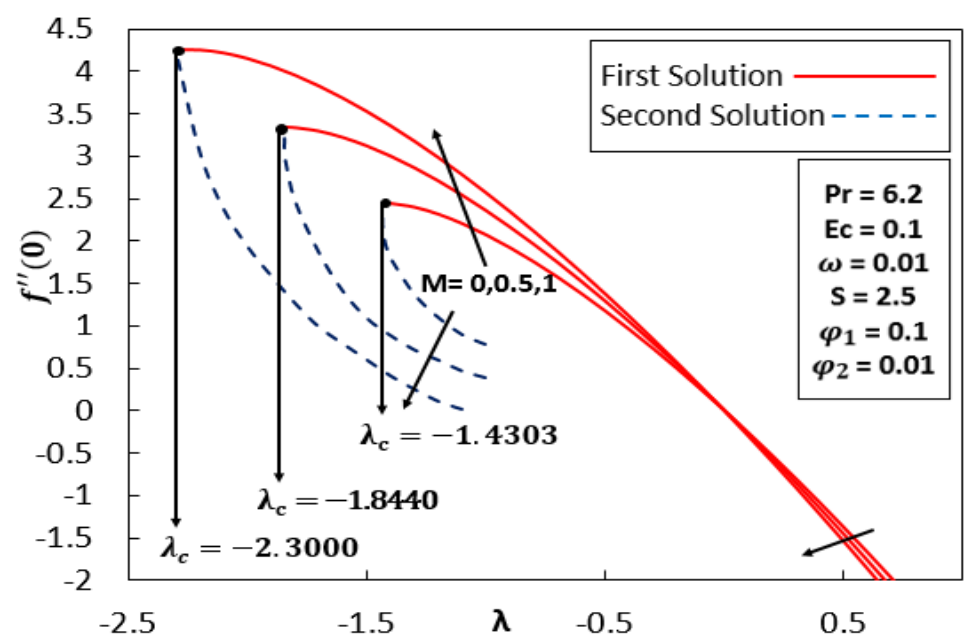

Fig. 11. Effect of $M$ on $f^{\prime \prime}(0)$ with respect to $\lambda$

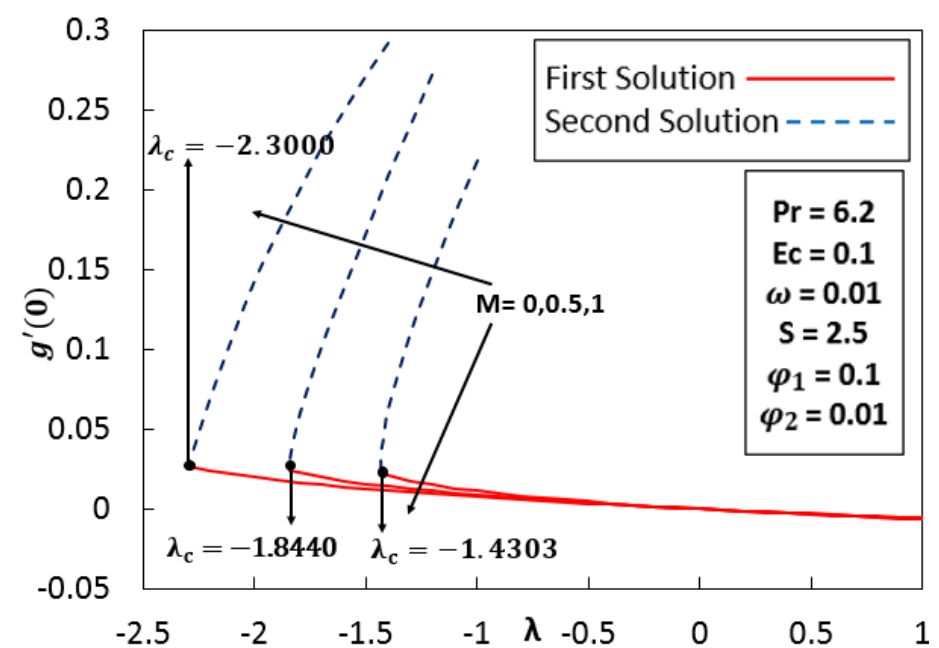

Fig. 12. Effect of $M$ on $g^{\prime}(0)$ with respect to $\lambda$

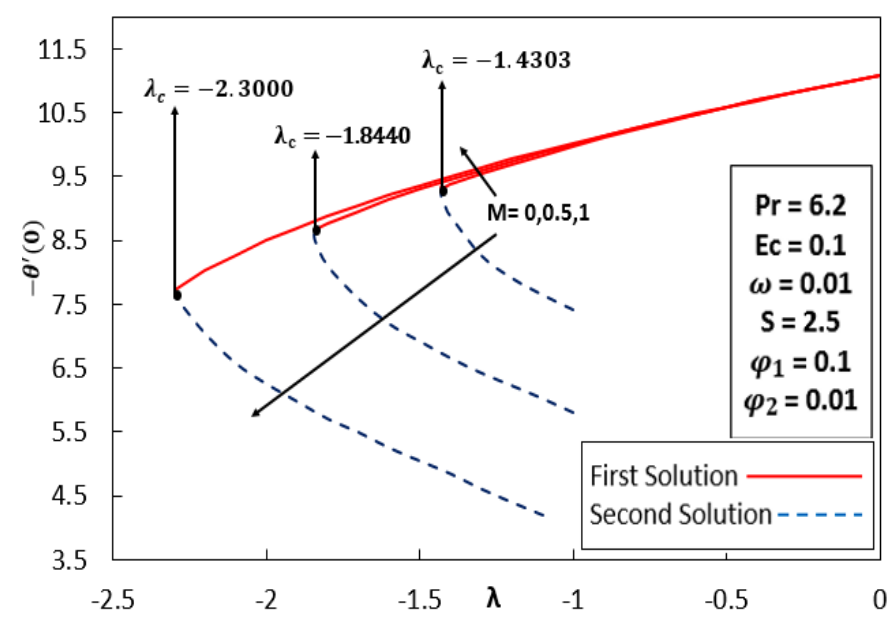

Fig. 13. Effect of $M$ on $-\theta^{\prime}(0)$ with respect to $\lambda$

The effects of rotational parameter $\omega$ on the velocity profile $f^{\prime}(\eta), g(\eta)$ and temperature profile $\theta(\eta)$ are exhibited in Figures 14-16. The chosen values of $\omega$ in Figures 14-16 are identical with the values of $\omega$ used in Anuar et al., [36]. In Figures 14-15, when the value of rotational parameter $\omega$ increases, both fluid velocity, and value of $g(\eta)$ are increased for both solutions. This indicates that 
the momentum boundary layer thickness increases with growing values of $\omega$ for both solutions. Observation in Figure 16 revealed that the thermal boundary layer thickness decreases for the first solution but increases for the second solution as the values of $\omega$ increases.

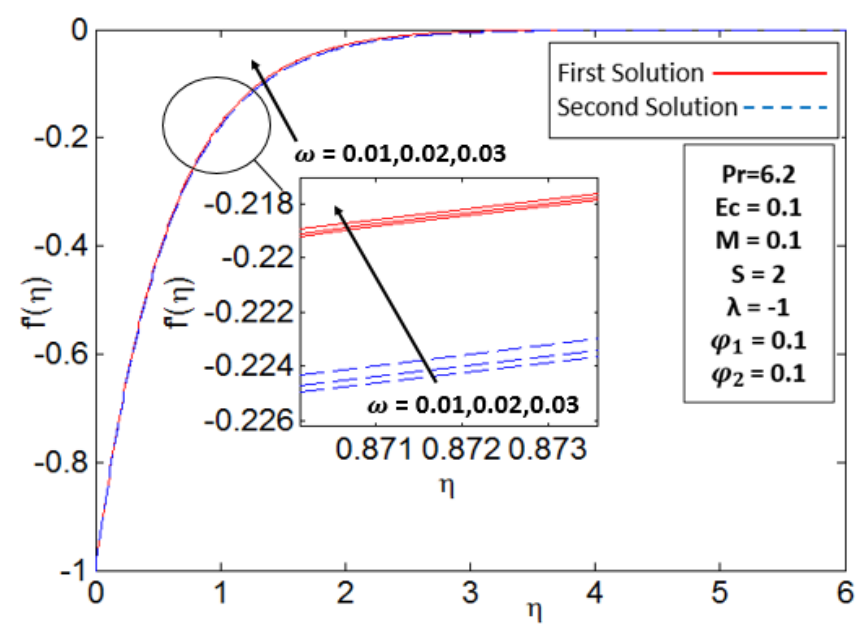

Fig. 14. Velocity profile for different $\omega$

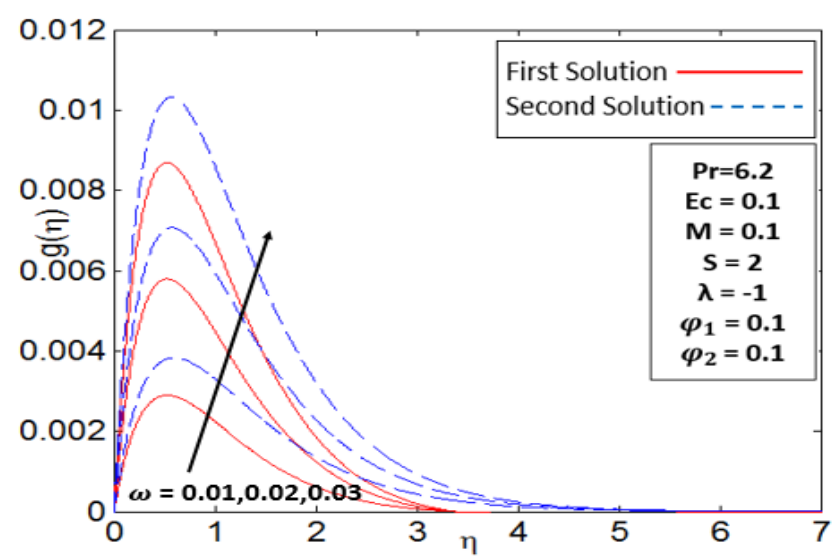

Fig. 15. Profile of $g(\eta)$ for different $\omega$

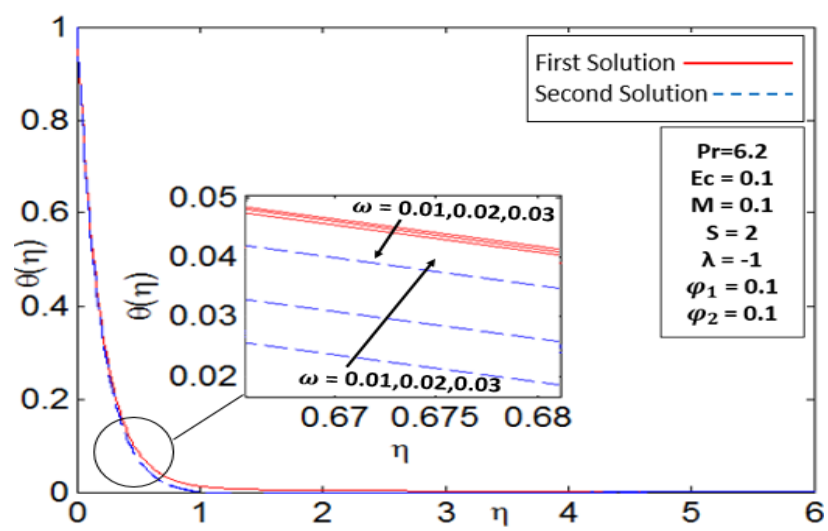

Fig. 16. Temperature profile for different $\omega$

Figure 17 illustrates the trend of the temperature profile $\theta(\eta)$ based on different values of the Eckert number Ec. This study picks the Eckert number to vary between 0.1 and 0.5 which found to be acceptable within the range of Eckert number previously considered by Khashi'ie et al., [50] (i.e. $0.01 \leq \mathrm{Ec} \leq 1)$. An increment in the value of Ec causes the temperature of the hybrid nanofluid to 
rise as well for both dual solutions. The intensity of heat transfer increases due to the increased heat generated through Joule heating. Similar observations can also be found in Yashkun et al., [41].

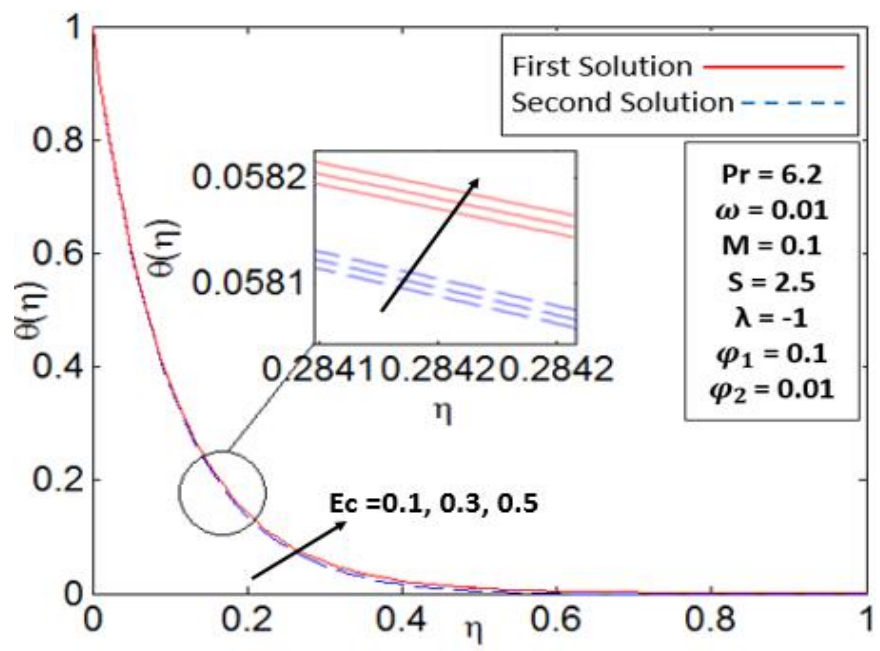

Fig. 17. Temperature profile for different Ec

Figure 18 examined the effect of Prandtl number Pr towards the temperature of the hybrid nanofluid. It shows an increment in Pr has lowered the temperature of the hybrid nanofluid for the dual solutions. In other words, thermal boundary layer thickness decreases as Pr increases. Although Figure 18 has observed the characteristics of the thermal boundary layer for $4 \leq \operatorname{Pr} \leq 6$, wider range values of $\operatorname{Pr}$ such as $0.5 \leq \operatorname{Pr} \leq 10$, is also permissible as reported in Waini et al., [44].

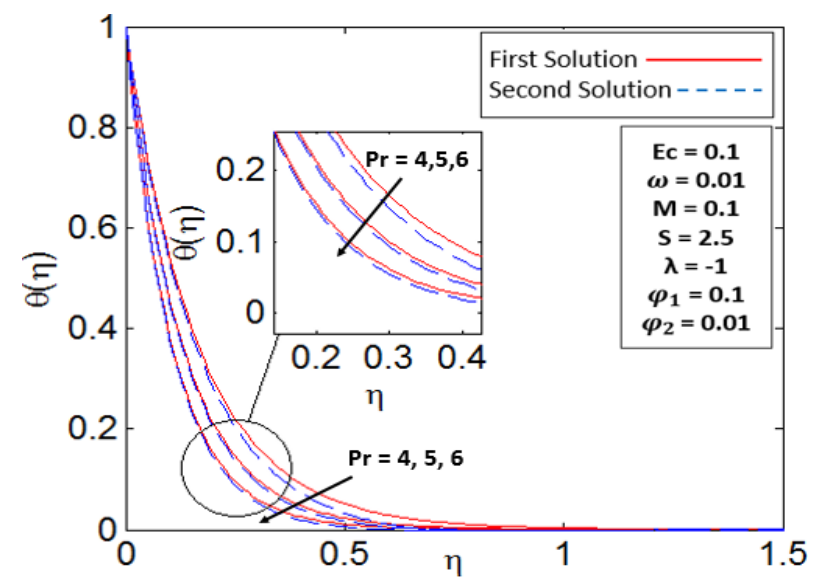

Fig. 18. Temperature profile for different $\mathrm{Pr}$

\section{Conclusions}

This study is prompted by the fact that hybrid nanofluid has a wide range of industrial applications. However, it also possesses numerous unknown physical characteristics or behaviours that are yet to be explored. Thus, this study focuses on the behaviour of the reduced skin friction $f^{\prime \prime}(0), g^{\prime}(0)$, reduced heat transfer $-\theta^{\prime}(0)$, velocity profile and temperature profile under the influence of stretching/shrinking, suction/injection, rotation, Joule heating, and MHD on a threedimensional $\mathrm{Al}_{2} \mathrm{O}_{3}-\mathrm{Cu}$ /water hybrid nanofluid flow with heat transfer over a permeable rotating shrinking/stretching sheet.

The above mentioned hybrid nanofluid flow is solved numerically using bvp4c solver which operates on the MATLAB computing platform. To be precise, all numerical and graphical results are 
produced by solving a system of higher order ODEs along with its boundary conditions that are transformed from the original governing PDEs via similarity transformation. The physical model proposed in this study and the coding in the bvp4c solver are verified and validated with the results obtained from previous studies. The main outcomes of the present study can be summarized as follows

i. Dual solutions are observed for suction parameter $S>S_{c}$ with the Cu nanoparticles volume fraction $\varphi_{2}$ varies from 0 to 0.1 .

ii. Dual solutions exist when the shrinking/stretching parameter $\lambda_{c} \leq \lambda \leq-1$ for shrinking sheet while unique solutions are observed for stretching sheet with different values of $\mathrm{Cu}$ nanoparticles volume fraction $\varphi_{2}$ and magnetic parameter $\mathrm{M}$.

iii. An increment in the magnetic parameter $M$ increases the velocity of the hybrid nanofluid, but at the same time, causing declination in the profile of $g(\eta)$ and temperature of the hybrid nanofluid.

iv. There is a direct proportion between the increment in the velocity, profile of $g(\eta)$, and temperature of the hybrid nanofluid, and the increment of rotational parameter $\omega$.

v. Thermal boundary layer thickness is enhanced when the Eckert number Ec is increased but reacts in the opposite manner when the Prandtl number Pr is increased.

Last but not least, modifications of the current proposed model to flow through complex body geometries, or inclusion of other physical parameters such as heat source/sink and partial slips into the current proposed model would constitute several recommendations for future studies.

\section{Acknowledgement}

This research was not funded by any grant.

\section{References}

[1] Choi, S. US, and Jeffrey A. Eastman. Enhancing thermal conductivity of fluids with nanoparticles. No. ANL/MSD/CP84938; CONF-951135-29. Argonne National Lab., IL (United States), 1995. https://www.osti.gov/servlets/purl/196525

[2] Sarkar, Jahar. "A critical review on convective heat transfer correlations of nanofluids." Renewable and Sustainable Energy Reviews 15, no. 6 (2011): 3271-3277. https://doi.org/10.1016/i.rser.2011.04.025

[3] Sarkar, Jahar, Pradyumna Ghosh, and Arjumand Adil. "A review on hybrid nanofluids: recent research, development and applications." Renewable and Sustainable Energy Reviews $43 \quad$ (2015): 164-177. https://doi.org/10.1016/i.rser.2014.11.023

[4] Lund, Liaquat Ali, Zurni Omar, Sumera Dero, Dumitru Baleanu, and Ilyas Khan. "Rotating 3D flow of hybrid nanofluid on exponentially shrinking sheet: Symmetrical solution and duality." Symmetry 12, no. 10 (2020): 1637. https://doi.org/10.3390/sym12101637

[5] Sakiadis, Byron C. "Boundary-layer behavior on continuous solid surfaces: I. Boundary-layer equations for twodimensional and axisymmetric flow." AIChE Journal 7, no. 1 (1961): 26-28. https://doi.org/10.1002/aic.690070108

[6] Crane, Lawrence J. "Flow past a stretching plate." Zeitschrift für angewandte Mathematik und Physik ZAMP 21, no. 4 (1970): 645-647. https://doi.org/10.1007/BF01587695

[7] Zaimi, K., A. Ishak, and I. Pop. "Stretching surface in rotating viscoelastic fluid." Applied Mathematics and Mechanics 34, no. 8 (2013): 945-952. https://doi.org/10.1007/s10483-013-1719-9

[8] Khan, W. A., and I. Pop. "Boundary-layer flow of a nanofluid past a stretching sheet." International Journal of Heat and Mass Transfer 53, no. 11-12 (2010): 2477-2483. https://doi.org/10.1016/i.ijheatmasstransfer.2010.01.032

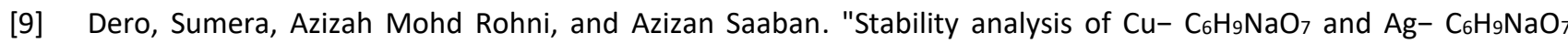
nanofluids with effect of viscous dissipation over stretching and shrinking surfaces using a single phase model." Heliyon 6, no. 3 (2020): e03510. https://doi.org/10.1016/i.heliyon.2020.e03510 
[10] Makinde, Oluwole D., and A. Aziz. "Boundary layer flow of a nanofluid past a stretching sheet with a convective boundary condition." International Journal of Thermal Sciences 50, no. 7 (2011): 1326-1332. https://doi.org/10.1016/j.ijthermalsci.2011.02.019

[11] Mansur, Syahira, and Anuar Ishak. "Unsteady boundary layer flow of a nanofluid over a stretching/shrinking sheet with a convective boundary condition." Journal of the Egyptian Mathematical Society 24, no. 4 (2016): 650-655. https://doi.org/10.1016/i.joems.2015.11.004

[12] Bachok, Norfifah, Anuar Ishak, and loan Pop. "Unsteady boundary-layer flow and heat transfer of a nanofluid over a permeable stretching/shrinking sheet." International Journal of Heat and Mass Transfer 55, no. 7-8 (2012): 2102 2109. https://doi.org/10.1016/i.ijheatmasstransfer.2011.12.013

[13] Nadeem, Sohail, M. Riaz Khan, and Arif Ullah Khan. "MHD stagnation point flow of viscous nanofluid over a curved surface." Physica Scripta 94, no. 11 (2019): 115207. https://doi.org/10.1088/1402-4896/ab1eb6

[14] Li, Xiangling, Arif Ullah Khan, Muhammad Riaz Khan, Sohail Nadeem, and Sami Ullah Khan. "Oblique stagnation point flow of nanofluids over stretching/shrinking sheet with Cattaneo-Christov heat flux model: existence of dual solution." Symmetry 11, no. 9 (2019): 1070. https://doi.org/10.3390/sym11091070

[15] Khan, M. Riaz, Kejia Pan, Arif Ullah Khan, and Naeem Ullah. "Comparative study on heat transfer in CNTs-water nanofluid over a curved surface." International Communications in Heat and Mass Transfer 116 (2020): 104707. https://doi.org/10.1016/j.icheatmasstransfer.2020.104707

[16] Nadeem, S., and Arif Ullah Khan. "MHD oblique stagnation point flow of nanofluid over an oscillatory stretching/shrinking sheet: existence of dual solutions." Physica Scripta 94, no. 7 (2019): 075204. https://doi.org/10.1088/1402-4896/ab0973

[17] Khan, M. R. "Numerical analysis of oblique stagnation point flow of nanofluid over a curved stretching/shrinking surface." Physica Scripta 95, no. 10 (2020): 105704. https://doi.org/10.1088/1402-4896/abb5c5

[18] Qaiser, Dania, Zhoushun Zheng, and Muhammad Riaz Khan. "Numerical assessment of mixed convection flow of Walters-B nanofluid over a stretching surface with Newtonian heating and mass transfer." Thermal Science and Engineering Progress (2020): 100801. https://doi.org/10.1016/i.tsep.2020.100801

[19] Li, Yi-Xia, Mohammed Hamed Alshbool, Yu-Pei Lv, Ilyas Khan, M. Riaz Khan, and Alibek Issakhov. "Heat and mass transfer in MHD Williamson nanofluid flow over an exponentially porous stretching surface." Case Studies in Thermal Engineering 26 (2021): 100975. https://doi.org/10.1016/i.csite.2021.100975

[20] Zhou, Cun-Jian, Awatef Abidi, Qiu-Hong Shi, M. Riaz Khan, Aysha Rehman, Alibek Issakhov, and Ahmed M. Galal. "Unsteady radiative slip flow of MHD Casson fluid over a permeable stretched surface subject to a non-uniform heat source." Case Studies in Thermal Engineering (2021): 101141. https://doi.org/10.1016/j.csite.2021.101141

[21] Zhang, Xiao-Hong, Awatef Abidi, A. El-Sayed Ahmed, M. Riaz Khan, M. A. El-Shorbagy, Meshal Shutaywi, Alibek Issakhov, and Ahmed M. Galal. "MHD stagnation point flow of nanofluid over curved stretching/shrinking surface subject to the influence of Joule heating and convective condition." Case Studies in Thermal Engineering (2021): 101184. https://doi.org/10.1016/i.csite.2021.101184

[22] Rohni, Azizah Mohd, Sumera Dero, and Azizan Saaban. "Triple Solutions and Stability Analysis of Mixed Convection Boundary Flow of Casson Nanofluid over an Exponentially Vertical Stretching/Shrinking Sheet." Journal of Advanced Research in Fluid Mechanics and Thermal Sciences 72, no. 1 (2020): 94-110. https://doi.org/10.37934/arfmts.72.1.94110

[23] Yashkun, Ubaidullah, Khairy Zaimi, Nor Ashikin Abu Bakar, and Mohammad Ferdows. "Nanofluid stagnation-point flow using Tiwari and Das model over a stretching/shrinking sheet with suction and slip effects." Journal of Advanced Research in Fluid Mechanics and Thermal Sciences 70, no. 1 (2020): 62-76. https://doi.org/10.37934/arfmts.70.1.6276

[24] Aladdin, Nur Adilah Liyana, Norfifah Bachok, and Nur Syazana Anuar. "MHD Stagnation Point Flow in Nanofluid Over Shrinking Surface Using Buongiorno's Model: A Stability Analysis." Journal of Advanced Research in Fluid Mechanics and Thermal Sciences 76, no. 3 (2020): 12-24. https://doi.org/10.37934/arfmts.76.3.1224

[25] Devi, SP Anjali, and S. Suriya Uma Devi. "Numerical investigation of hydromagnetic hybrid $\mathrm{Cu}-\mathrm{Al}_{2} \mathrm{O}_{3} /$ water nanofluid flow over a permeable stretching sheet with suction." International Journal of Nonlinear Sciences and Numerical Simulation 17, no. 5 (2016): 249-257. https://doi.org/10.1515/ijnsns-2016-0037

[26] Huminic, Gabriela, and Angel Huminic. "Hybrid nanofluids for heat transfer applications-a state-of-the-art review." International Journal of Heat and Mass Transfer $125 \quad$ (2018): 82-103. https://doi.org/10.1016/j.ijheatmasstransfer.2018.04.059

[27] Waini, Iskandar, Anuar Ishak, and loan Pop. "Hybrid nanofluid flow and heat transfer over a nonlinear permeable stretching/shrinking surface." International Journal of Numerical Methods for Heat \& Fluid Flow 29, no. 9 (2019): 3110-3127. https://doi.org/10.1108/HFF-01-2019-0057 
[28] Waini, Iskandar, Anuar Ishak, and loan Pop. "Unsteady flow and heat transfer past a stretching/shrinking sheet in a hybrid nanofluid." International Journal of Heat and Mass Transfer 136 (2019): $288-297$. https://doi.org/10.1016/i.ijheatmasstransfer.2019.02.101

[29] Waini, Iskandar, Anuar Ishak, and loan Pop. "Hybrid nanofluid flow towards a stagnation point on an exponentially stretching/shrinking vertical sheet with buoyancy effects." International Journal of Numerical Methods for Heat \& Fluid Flow 31, no. 1 (2020): 216-235. https://doi.org/10.1108/HFF-02-2020-0086

[30] Urmi, Wajiha Tasnim, A. S. Shafiqah, Md Mustafizur Rahman, Kumaran Kadirgama, and Md Abdul Maleque. "Preparation Methods and Challenges of Hybrid Nanofluids: A Review." Journal of Advanced Research in Fluid Mechanics and Thermal Sciences 78, no. 2 (2021): 56-66. https://doi.org/10.37934/arfmts.78.2.5666

[31] Khan, M. Riaz, Kejia Pan, Arif Ullah Khan, and S. Nadeem. "Dual solutions for mixed convection flow of SiO ${ }_{2}-$ $\mathrm{Al}_{2} \mathrm{O}_{3}$ /water hybrid nanofluid near the stagnation point over a curved surface." Physica A: Statistical Mechanics and its Applications 547 (2020): 123959.https://doi.org/10.1016/i.physa.2019.123959

[32] Khan, M. Riaz, Mingxia Li, Shipeng Mao, Rashid Ali, and Suliman Khan. "Comparative study on heat transfer and friction drag in the flow of various hybrid nanofluids effected by aligned magnetic field and nonlinear radiation." Scientific Reports 11, no. 1 (2021): 1-14. https://doi.org/10.1038/s41598-021-81581-1

[33] Hussain, Azad, Mohammed Hamed Alshbool, Aishah Abdussattar, Aysha Rehman, Hijaz Ahmad, Taher A. Nofal, and M. Riaz Khan. "A computational model for hybrid nanofluid flow on a rotating surface in the existence of convective condition." Case Studies in Thermal Engineering (2021): 101089. https://doi.org/10.1016/i.csite.2021.101089

[34] Hayat, Tanzila, and S. Nadeem. "Heat transfer enhancement with Ag-CuO/water hybrid nanofluid." Results in Physics 7 (2017): 2317-2324. https://doi.org/10.1016/i.rinp.2017.06.034

[35] Hayat, Tanzila, S. Nadeem, and A. U. Khan. "Rotating flow of Ag-CuO/ $\mathrm{H}_{2} \mathrm{O}$ hybrid nanofluid with radiation and partial slip boundary effects." The European Physical Journal E 41, no. 6 (2018): 1-9. https://doi.org/10.1140/epje/i2018$11682-y$

[36] Anuar, Nur Syazana, Norfifah Bachok, and loan Pop. "Radiative hybrid nanofluid flow past a rotating permeable stretching/shrinking sheet." International Journal of Numerical Methods for Heat \& Fluid Flow 31, no. 3 (2020): $914-$ 932. https://doi.org/10.1108/HFF-03-2020-0149

[37] Bhattacharyya, Krishnendu, and Kuppalapalle Vajravelu. "Stagnation-point flow and heat transfer over an exponentially shrinking sheet." Communications in Nonlinear Science and Numerical Simulation 17, no. 7 (2012): 2728-2734. https://doi.org/10.1016/j.cnsns.2011.11.011

[38] Anuar, Nur Syazana, Norfifah Bachok, Norihan Md Arifin, and Haliza Rosali. "Effect of suction/injection on stagnation point flow of hybrid nanofluid over an exponentially shrinking sheet with stability analysis." CFD Letters 11, no. 12 (2019): 21-33.

[39] Waini, Iskandar, Anuar Ishak, and loan Pop. "Flow and heat transfer along a permeable stretching/shrinking curved surface in a hybrid nanofluid." Physica Scripta 94, no. 10 (2019): 105219. https://doi.org/10.1088/14024896/ab0fd5

[40] Hayat, Tasawar, Arsalan Aziz, Taseer Muhammad, and Ahmed Alsaedi. "Significance of homogeneousheterogeneous reactions in Darcy-Forchheimer three-dimensional rotating flow of carbon nanotubes." Journal of Thermal Analysis and Calorimetry 139, no. 1 (2020): 183-195. https://doi.org/10.1007/s10973-019-08316-3

[41] Yashkun, Ubaidullah, Khairy Zaimi, Anuar Ishak, loan Pop, and Rabeb Sidaoui. "Hybrid nanofluid flow through an exponentially stretching/shrinking sheet with mixed convection and Joule heating." International Journal of Numerical Methods for Heat \& Fluid Flow 31, no. 3 (2020): 1014-1031. https://doi.org/10.1108/HFF-07-2020-0423

[42] Devi, S. Suriya Uma, and SP Anjali Devi. "Numerical investigation of three-dimensional hybrid $\mathrm{Cu}-\mathrm{Al}_{2} \mathrm{O}_{3} /$ water nanofluid flow over a stretching sheet with effecting Lorentz force subject to Newtonian heating." Canadian Journal of Physics 94, no. 5 (2016): 490-496. https://doi.org/10.1139/cjp-2015-0799

[43] Aly, Emad H., and loan Pop. "MHD flow and heat transfer over a permeable stretching/shrinking sheet in a hybrid nanofluid with a convective boundary condition." International Journal of Numerical Methods for Heat \& Fluid Flow 29, no. 9 (2019): 3012-3038. https://doi.org/10.1108/HFF-12-2018-0794

[44] Waini, Iskandar, Anuar Ishak, and Ioan Pop. "Hybrid nanofluid flow induced by an exponentially shrinking sheet." Chinese Journal of Physics 68 (2020): 468-482. https://doi.org/10.1016/i.cjph.2019.12.015

[45] Lund, Liaquat Ali, Zurni Omar, Ilyas Khan, and El-Sayed M. Sherif. "Dual solutions and stability analysis of a hybrid nanofluid over a stretching/shrinking sheet executing MHD flow." Symmetry 12, no. 2 (2020): 276. https://doi.org/10.3390/sym12020276

[46] Ali Lund, Liaquat, Zurni Omar, Jawad Raza, Ilyas Khan, and El-Sayed M. Sherif. "Effects of Stefan blowing and slip conditions on unsteady MHD casson nanofluid flow over an unsteady shrinking sheet: dual solutions." Symmetry 12, no. 3 (2020): 487. https://doi.org/10.3390/sym12030487 
[47] Alarifi, Ibrahim M., Ahmed G. Abokhalil, M. Osman, Liaquat Ali Lund, Mossaad Ben Ayed, Hafedh Belmabrouk, and Iskander Tlili. "MHD flow and heat transfer over vertical stretching sheet with heat sink or source effect." Symmetry 11, no. 3 (2019): 297. https://doi.org/10.3390/sym11030297

[48] Zainal, Nurul Amira, Roslinda Nazar, Kohilavani Naganthran, and loan Pop. "MHD flow and heat transfer of hybrid nanofluid over a permeable moving surface in the presence of thermal radiation." International Journal of Numerical Methods for Heat \& Fluid Flow 59, no.3 (2020): 1787-1798. https://doi.org/10.1108/HFF-03-2020-0126

[49] Salehi, Sajad, Amin Nori, Kh Hosseinzadeh, and D. D. Ganji. "Hydrothermal analysis of MHD squeezing mixture fluid suspended by hybrid nanoparticles between two parallel plates." Case Studies in Thermal Engineering 21 (2020): 100650. https://doi.org/10.1016/i.csite.2020.100650

[50] Khashi'ie, Najiyah Safwa, Norihan Md Arifin, Roslinda Nazar, Ezad Hafidz Hafidzuddin, Nadihah Wahi, and Ioan Pop. "Magnetohydrodynamics (MHD) axisymmetric flow and heat transfer of a hybrid nanofluid past a radially permeable stretching/shrinking sheet with Joule heating." Chinese Journal of Physics 64 (2020): $251-263$. https://doi.org/10.1016/i.cjph.2019.11.008

[51] Yan, Liang, Sumera Dero, Ilyas Khan, Irshad Ali Mari, Dumitru Baleanu, Kottakkaran Sooppy Nisar, El-Sayed M. Sherif, and Hany S. Abdo. "Dual Solutions and Stability Analysis of Magnetized Hybrid Nanofluid with Joule Heating and Multiple Slip Conditions." Processes 8, no. 3 (2020): 332. https://doi.org/10.3390/pr8030332

[52] Chamkha, Ali J., A. S. Dogonchi, and D. D. Ganji. "Magneto-hydrodynamic flow and heat transfer of a hybrid nanofluid in a rotating system among two surfaces in the presence of thermal radiation and Joule heating." AIP Advances 9, no. 2 (2019): 025103. https://doi.org/10.1063/1.5086247

[53] Mahanthesh, B., S. A. Shehzad, T. Ambreen, and S. U. Khan. "Significance of Joule heating and viscous heating on heat transport of $\mathrm{MoS}_{2}-\mathrm{Ag}$ hybrid nanofluid past an isothermal wedge." Journal of Thermal Analysis and Calorimetry (2020): 1-9. https://doi.org/10.1007/s10973-020-09578-y

[54] Aziz, Asim, Wasim Jamshed, Yasir Ali, and Moniba Shams. "Heat transfer and entropy analysis of Maxwell hybrid nanofluid including effects of inclined magnetic field, Joule heating and thermal radiation." Discrete \& Continuous Dynamical Systems-S 13, no. 10 (2020): 2667. https://doi.org/10.3934/dcdss.2020142

[55] Ahmed, Awais, Masood Khan, Jawad Ahmed, Abdul Hafeez, and Zahoor Iqbal. "Unsteady stagnation point flow of Maxwell nanofluid over stretching disk with joule heating." Arabian Journal for Science and Engineering (2020): 112. https://doi.org/10.1007/s13369-020-04468-9

[56] Tiwari, Raj Kamal, and Manab Kumar Das. "Heat transfer augmentation in a two-sided lid-driven differentially heated square cavity utilizing nanofluids." International Journal of heat and Mass transfer 50, no. 9-10 (2007): 20022018. https://doi.org/10.1016/j.ijheatmasstransfer.2006.09.034

[57] Lund, Liaquat Ali, Zurni Omar, Ilyas Khan, Seifedine Kadry, Seungmin Rho, Irshad Ali Mari, and Kottakkaran Sooppy Nisar. "Effect of viscous dissipation in heat transfer of MHD flow of micropolar fluid partial slip conditions: Dual solutions and stability analysis." Energies 12, no. 24 (2019): 4617. https://doi.org/10.3390/en12244617

[58] Sajid, M., T. Javed, and T. Hayat. "MHD rotating flow of a viscous fluid over a shrinking surface." Nonlinear Dynamics 51, no. 1 (2008): 259-265. https://doi.org/10.1007/s11071-007-9208-3

[59] Hale, N. P. "A sixth-order extension to the matlab bvp4c software of j. kierzenka and I. shampine." Department of Mathematics, Imperial College London (2006).

[60] Mustafa, M., A. Mushtaq, T. Hayat, and A. Alsaedi. "Rotating flow of magnetite-water nanofluid over a stretching surface inspired by non-linear thermal radiation." Plos One 11, no. 2 (2016): e0149304. https://doi.org/10.1371/journal.pone.0149304 